\title{
MAX WEBER: \\ UM PENSADOR DA CULTURA
}

\section{RESU MO}

ÊnioPassiani

O moderno capitalismo não possui apenas raízes políticas e econômicas, mas também deve sua origem a um novo estilo de vida, um novo ethos. Tal conjunto de valores, o espírito capitalista do qual nos fala Max W eber, permite descortinar a dimensão e a dinâmica da cultura no processo de formação do capital ismo ocidental.

Palavras-chave M ax W eber; capitalismo; cul tura; ethos; valores.

\section{ABST RACT}

The modern capitalism not only owns political and economic roots but also owes its origin to a new life style - a new ethos. Such set of values - the capital ism spirit, according to Max Weber - allows us to uncover the dimension and dynamics of culture in the western capitalism formation process.

K ey words: M ax W eber; capital ism; culture; ethos; val ues.

\section{Introdução}

H arvey Goldman (1993) escreveu que o trabal ho de Weber, mais do que nunca, é de rel evante importância para estudarmos o mundo social, dada a amplitude de áreas que cobriu. Poderíamos supor que um leque tão variado de pesquisas implicaria um obstáculo para 0 entendimento do conjunto da sociologia de Max Weber, ou que teríamos dificuldades até mesmo de lembrar quais foram esses trabal hos. Rapidamente, sem maiores esforços de memória, podemos citar alguns temas sobre os quais o sociólogo al emão se debruçou: religiões, burocracia, formas de dominação, partidos políticos, estratificação social e Direito. Ao contrário do que tal variedade pode sugerir, não é nesse ponto que se localiza a dificuldade em entendermos a obra de W eber, mas justamente o oposto: deparamos com uma fantástica coerência. A sociologia weberiana representa um árduo exercício de leitura e compreensão em razão de sua poderosa lógica interna, coerência e riqueza teóricas.

$\mathrm{N}$ a verdade, é possível visualizarmos alguns fios condutores da teoria weberiana que unem os seus vários trabalhos. Alguns de seus temas já são amplamente conhecidos, como o capitalismo ocidental, a religião e a burocracia. $\mathrm{N}$ este artigo, propomos uma outra perspectiva que, a nosso ver, também constitui uma vertente importante para decifrarmos os textos weberianos: a presença da dimensão da cultura em 
suas análises. N ão temos a pretensão de arrogar, aqui, qualquer originalidade ou novidade para este ensaio, pois outros autores (KALBERG, 1996; GEERTZ, 1978; SW IN DLER, 1986) já al ertaram para a presença e a importância da questão da cultura no pensamento de W eber. Da mesma forma, não temos o objetivo de sistematizar um conceito de cultura weberiano. A ambição do presente artigo é apenas acentuar a relevância que a dimensão cultural tem na sociologia de $M a x$ Weber $e$ chamar a atenção para 0 fato de que 0 estudo da cultura também era uma de suas preocupações, que, ao que parece, foi relegada a um segundo plano pelos comentadores.

\section{Weber e a Sociologia da Cultura}

Diante de tantas e tão rápidas transformações do mundo contemporâneo, talvez seja lícito perguntar: por que estudar Weber? $\mathrm{N}$ ão seria mais apropriado dedicarmo-nos a autores mais recentes? $\mathrm{H}$ arvey Goldman (1993) oferece uma resposta interessante para a questão: segundo ele, muitos aspectos dos textos clássicos de Marx, Durkheim e W eber permanecem invisíveis. A tarefa da interpretação é tornar os significados dos textos visíveis, expor os fundamentos ou estruturas profundas dos conceitos para mostrar as bases sobre as quais repousam, descobrir a gramática que governa seu uso e explorar a lógica e as implicações de conceitos e teorias (GOLDMAN, 1993: 854). Portanto, além da tarefa de interpretação, ainda existe a de reinterpretação que, por sua vez, enriquece o trabalho empírico e teórico dos pesquisadores em geral. W eber nos fornece um arcabouço teórico e metodológico bastante rico para enfrentarmos os problemas sociológicos atuais, inclusive aqueles que dizem respeito à dimensão da cultura.

De acordo com Stephen K alberg (1996), a realidade social empírica, para Weber, inclui uma dimensão cultural sociologicamente relevante, e ela não é apenas o resultado de forças políticas e econômicas; por conseguinte, a própria Sociologia não pode restringir-se às estruturas sociais e aos interesses econômicos e de poder. 0 próprio W eber rejeitaria a hipótese de que uma ética econômica ou o espírito do capitalismo pudessem ser explicados apenas com referência à estrutura social.

Max W eber investigou se forças culturais, tais como a orientação da ação e certas doutrinas religiosas, influenciaram na formação de um espírito capitalista. Os fatores culturais, portanto, têm papel central na obra do autor. 0 moderno capitalismo só pode ser compreendido na 
referência a um novo thos e conduta de vida, um novo conjunto de valores, cujas raízes não são políticas e tampouco econômicas. A origem de uma vida metódica e racional - matéria-prima para a formação de um espírito capitalista - não está na economia ou na política, nem em um profundo desejo de riqueza, mas num conjunto de valores religiosos que fortal eceram e introduziram uma sistematização da conduta ética. W eber "tenta demonstrar que os comportamentos econômicos da classe dos empresários capitalistas são compreensíveis somente se levarmos em consideração a sua concepção de mundo e seu sistema de valores" (CU CHE, 1999: 161). Se, inicialmente, tal conduta é fortemente influenciada por valores religiosos, aos poucos ela se seculariza, ultrapassando os limites éticos e morais impostos a princípio. Vale assinalar que a R eforma foi um catalisador na transformação da cultura urbana ocidental, que estimulou - mas não determinou - uma nova forma de racionalidade.

0 novo ethos (que diz respeito a um estilo ou modo de vida e costumes até então inéditos), conduta de vida ancorada em um crescente e amplo processo de racionalização, vai tomando conta de todas as esferas da vida social. A cultura ocidental capitalista enfatiza a razão, a estabilidade, a coerência, a disciplina e o controle sobre o mundo: uma cultura dedicada ao trabalho e à transformação do meio humano. Segundo Bryan Turner (1993), encontramos, em Ética protestante e o espírito do capitalismo, a visão central das origens, natureza e efeitos da racionalização.

A Sociologia da Cultura de W eber tem como um de seus objetivos investigar a cultura ocidental, o que necessariamente exige o estudo do capitalismo. Schluchter (1981), por exemplo, assinala que, para W eber, o capitalismo e as formas de racionalidade engendradas em seu interior aparecem como manifestações culturais específicas do 0 cidente. Além de Schluchter, Turner (1993) adota uma linha de argumentação bastante semel hante: as raízes da racional idade e o processo de racionalização repousam profundamente na história cultural do 0 cidente.

0 resultado do processo de racionalização que se desenrola no Ocidente produziu um mundo dominado por uma estrutura burocrática altamente reguladora. A racional ização da cultura (ou a cultura da razão) implica o controle das paixões e do comportamento em público, ou seja, produz a racionalização da própria ação social dos agentes. M clntosh (1983) argumenta que o trabal ho de Weber - neste caso preferimos conferir especificidade, utilizando o termo 'sociologia weberiana da cultura' em vez de trabalho - apresenta uma forte crítica à burocratização de toda a ação social, de toda a vida social. 0 alvo de 
W eber é a moderna sociedade industrial avançada em todas as suas formas. 0 problema é que a crítica acurada e sensível do sociólogo alemão não oferece saídas ou alternativas: sua Sociologia da Cultura é crítica, mas resignada, como sugere Cohn. (1979)

\section{A cultura na obra de Weber}

É possível demonstrar a coerência de uma sociologia da cultura de inspiração weberiana nos seus comentadores e também assinalar a presença e a importância do universo da cultura nos textos do próprio $W$ eber, tanto naqueles que dizem respeito a uma sociologia mais substantiva, i. e., de orientação mais teórica, quanto nos de caráter metodológico.

N o seu M etodologia das C iências Sociais, W eber afirma que o caráter de fenômeno socioeconômico de um processo não é algo que the seja inerente; "pelo contrário, ele está condicionado pela orientação do nosso interesse de conhecimento e essa orientação define-se em conformidade com o significado cultural que atribuímos ao evento em questão, em cada caso particular. Portanto, são os processos da vida cultural que contêm o significado dos eventos sócio-econômicos" (W EBER, 1992: 118 - grifos nossos; 1ạ edição 1982). Se, por um lado, um determinado fenômeno social, seja qual for, possui um significado cultural, por outro, os fenômenos culturais não podem ser deduzidos como produto ou como função de determinados interesses materiais. Por isso, W eber criticava veementemente aquelas teorias que preconizavam que os fatos sociais que não pudessem ser analisados a partir de seus motivos econômicos deveriam ser considerados cientificamente insignificantes. Destarte, o conhecimento dos acontecimentos culturais, na teoria weberiana, só pode ser construído com base na significação que a realidade da vida possui para nós. Tomando como pressuposto que os fenômenos sociais e econômicos possuem um significado cultural, Weber se deteve nos motivos pelos quais se originaram a ética religiosa da negação do mundo (elemento intrínseco ao processo de racionalização ocidental) e as direções que tomou para, a partir daí, esclarecer seu provável significado. (W EBER, 1982; 1ạ ed. 1915)

H ouve uma combinação de fatores, no Ocidente, que permitiu a emergência de fenômenos culturais dotados de um desenvolvimento mais amplo em seu valor e significado. Fatores materiais e espirituais contribuíram para a consolidação do capitalismo de tipo ociden- 
tal: a separação da empresa da economia doméstica, a criação de uma contabilidade racional, a organização racional do trabal ho, o desenvolvimento de possibilidades técnicas, o desejo capitalista de acumular riquezas sem usufruí-las - desejo este orientado "pela difusão dos valores ascéticos secularizados" (CU CHE, 1999: 165), ou seja, a cultura. 0 desenvolvimento do capitalismo ocidental é fruto da conjugação de fatores econômicos e espirituais - estes últimos correspondem a valores que moldaram o comportamento dos agentes sociais e regulamentaram sua conduta. $N$ esse sentido, observamos a formação de uma 'mentalidade econômica', de um ethos correspondente a um determinado sistema econômico. Portanto, mesmo os fatores materiais são prenhes de significados culturais.

Para W eber, entretanto, restava ainda investigar qual a origem desse conjunto de idéias que motivou o surgimento e a consolidação de um certo tipo de conduta. Ele não acreditava na tese do materialismo histórico, segundo a qual idéias, valores e representações constituem 0 produto de condições econômicas específicas: "A questão das forças motivadoras da expansão do capitalismo não é, em primeira instância, uma questão de origem das somas de capital disponíveis para uso capitalístico, mas, principalmente, do desenvol vimento do espírito do capitalismo" (W EBER, 1996: 44; 1ª ed. 1905). Tal espírito ou thos possuía estreitas relações com a ascese cristã, mais especificamente a protestante.

Segundo o pensador, para que um modo de vida se adaptasse tão bem às particularidades do capitalismo, ele não poderia originar-se apenas em indivíduos isolados, mas constituir-se como um modo de vida comum a grupos inteiros de homens, i.e., deveria haver um espírito que envolvesse os sujeitos sociais e os motivasse a agir de determinada maneira, o que contribuiria decisivamente para a formação de uma ordem social capitalista. É importante lembrar que a noção de 'espírito' utilizada por W eber não guarda relação nenhuma com aquela elaborada por $\mathrm{H}$ egel. Ao contrário da filosofia ideal ista hegeliana, o 'espírito do capitalismo' a que se refere está fincado em sólidas bases sócio-históricas e remete à formação de um complexo cultural portador de afinidades (eletivas) com o sistema capital ista. Tal espírito construiu a imagem segundo a qual o trabal ho deve ser executado como um fim absoluto em si mesmo, como uma "vocação" (W EBER, 1996; 1ạ. Edição 1905). A valorização do cumprimento do dever dentro das profissões seculares conferiu sentido a este termo, atribuindo um significado religioso ao trabal ho secular cotidiano: 
Foi, portanto, nesse conceito de vocação que se manifestou o dogma central de todos os ramos do Protestantismo, descartado pela divisão católica dos preceitos éticos em praecepta e consilia [preceitos e deliberações, respectivamente], e segundo a qual a única maneira de viver aceitável para Deus não estava na superação da moralidade secular pela ascese monástica, mas sim no cumprimento das tarefas do século, imposta ao indivíduo pela sua posição no mundo. N isso é que está a sua vocação." (Id.Ib.: 53)

A concepção de vocação desenvolvida por Lutero é, em certo sentido, complementada pela de predestinação, elaborada por Calvino. Para este, a fé tinha de ser provada por seus resultados objetivos, a fim de proporcionar uma base segura para a certitudo salutis (que poderia ser traduzida como certeza da graça), mas o próprio W eber salienta que a expressão possuía um sentido mais profundo entre os calvinistas, algo como "responsabilidade de reconhecimento do estado de graça" (Id.Ib.:76). $\mathrm{N}$ a doutrina calvinista, as boas obras não eram um meio de obtenção da salvação, mas um sinal de escol ha; representavam a libertação do medo da condenação. Assim, o calvinista criava sua própria libertação, ou a convicção disto. Tal criação, por sua vez, gerava um sistemático autocontrole sobre todas as atividades cotidianas (ld.lb.). Esse rígido controle criava uma racional ização cada vez maior do mundo e a eliminação da mágica como meio de sal vação. (W EBER, 1982; $1^{\text {a }}$ ed. 1915)

Observamos que ambas doutrinas, a luterana e a calvinista, como um conjunto de idéias e val ores - portanto, de elementos culturais - moldam o comportamento dos sujeitos sociais e orientam suas ações, conferindo um sentido muito particular a esse novo ethos econômico que, por seu turno, constituiu-se num componente vital do espírito capitalista: "Um dos componentes fundamentais do espírito do moderno capitalismo, e não apenas deste, mas de toda a cultura moderna: a conduta racional baseada na idéia da vocação, nasceu do espírito da ascese cristã" (WEBER, 1996: 130; $1^{\text {a }}$ ed. 1905). Quando 0 ascetismo ultrapassa os limites dos mosteiros e chega à vida profissional, passando a influenciar a moralidade secular, contribui para a formação da moderna ordem econômica e técnica ligada à produção por meio da máquina, o que determina, de maneira irresistível, o estilo de vida de todo indivíduo nascido sob esse sistema. Aos poucos, o modo de vida típico do capitalismo foi se destacando de um ethos de base religiosa. "D esde que 0 ascetismo começou a remodelar o mundo e a nele se desenvolver, os bens materiais foram assumindo uma crescente, e, finalmente, uma inexorável força sobre os homens, como nunca antes na H istória" (Id.Ib.: 
130-131). Mas os bens materiais só possuem tal força porque Ihes foram atribuídos novos significados culturais ao longo da história.

\section{Releituras de Max Weber e análises da cultura: Clifford Geertz eAnn Swindler}

A partir das proposições teóricas de Weber, Geertz elabora, com criatividade, uma nova forma de abordagem etnográfica: a Antropologia Interpretativa. Aqui, podemos constatar a importância da leitura e reinterpretação dos textos clássicos, tal como apontamos nas seções I e ll. M unido de outras referências teóricas, Geertz reinterpreta al guns conceitos weberianos. Com isso, o antropólogo é capaz, ao mesmo tempo, de arquitetar seu próprio quadro teórico e iluminar certos aspectos dos textos de W eber que permaneciam obscuros, de difícil compreensão.

0 conceito de cultura adotado por Geertz é, segundo ele, essencialmente semiótico. Tal como W eber, ele acredita "que o homem é um animal amarrado a teias de significados que ele mesmo teceu" (GEERTZ, 1978: 15). 0 conceito, pois, não se enquadra nos moldes de uma ciência experimental à procura de 'leis gerais', mas de uma ciência interpretativa à procura do significado. É fácil notar que, nesse ponto, Geertz transplanta as indicações metodológicas e a sociologia interpretativa de Weber para o campo da Antropologia.

Para Geertz, é importante apanhar o significado 'oculto' de um gesto, de uma ação social. E quais os códigos socioculturais que 0 ator social emprega e movimenta? Qual o sentido da ação? De acordo com 0 antropólogo norte-americano, o sentido deve ser buscado num 'código público', i.e., socialmente compartilhado. Se há um código público, socialmente aceito, é porque, provavelmente, a sociedade possui um 'espírito' que também é coletivamente partilhado. Mais uma vez percebemos ecos weberianos na Antropologia Interpretativa/ Culturalista de Geertz, que, de acordo com os cânones antropológicos, entende que a investigação de uma cultura implica observarmos e descrevermos o comportamento humano como uma ação simbólica que significa e se desenvolve nos inúmeros contextos que compõem uma dada sociedade, cada qual ressignificando incessantemente val ores, idéias e visões de mundo. É esta ação social (e não o símbolo em si mesmo), por intermédio da qual as formas culturais encontram articulação, que se converte na matéria-prima da análise sociológica. N esse sentido, para Geertz, a cultura deve ser entendida como um conjunto de formas sim- 
bólicas publicamente disponíveis - i. e, socialmente compartilhadas - a partir das quais as pessoas experimentam e expressam significado.

Em artigo publicado em 1986, a pesquisadora Ann Swindler avança no caminho aberto por Geertz e propõe uma análise da cultura baseada em três pontos: 1) a imagem da cultura como uma 'caixa de ferramentas' de símbolos, histórias, rituais e visões de mundo; 2) a focal ização da cultura por meio da perspectiva de estratégias de ação; 3 ) o entendimento de que a cultura não define os fins da ação, mas provê componentes que são utilizados para construir estratégias de ação.

Segundo a autora, a explicação cultural fundamentada no estudo de valores apresenta fal has. E aí realiza uma crítica a W eber: neste, os seres humanos são motivados por interesses ideais e materiais, os interesses são 0 combustível da ação. Para Swindler, "a teoria dos valores sobrevive em parte, sem dúvida, devido à plausibilidade intuitiva em nossa própria cultura, que supõe que toda ação seja, em última instância, governada por al guns esquemas de meios e fins. A cultura modela a ação ao definir o que as pessoas querem" (1986: 274, tradução nossa). Entretanto, saber o que as pessoas querem é de pouca ajuda para explicar sua ação. Para ela, o comportamento de grupos ou sociedades é mais bem explicado como habilidades e hábitos culturalmente modelados do que como val ores e preferências.

Em É tica protestante e o espí rito do capital ismo, W eber argumenta que determinados fins (a sal vação) foram criados por idéias (a ética protestante) que influenciaram vigorosamente a conduta dos indivíduos; no entanto, tais fins e idéias excederam as fronteiras da religião. Por isso, ele reconhecia uma certa continuidade entre o calvinismo e a ética secular de Benjamin Franklin. Mas, indaga Swindler: como compreender o 'thos da ação' diante da mudança de idéi as? A continuidade mencionada sugere que o que permanece é o modo como a ação é organizada, e não seus fins.

A autora não crê que as pessoas orientem suas ações baseadas apenas em interesses ou valores, pois a ação está integrada em esquemas mais amplos denominados pela autora como "estratégias de ação" (SW IN D LER,1986: 276-277), encaradas como um modo geral de organizar a ação, incorporando hábitos, sensibilidades, visões de mundo etc. As pessoas não constroem linhas de ação a partir do nada: "Em vez disso, constroem cadeias de ação a partir de al guns elos pré-fabricados. A cultura influencia a ação por meio da forma e da organização desses elos, e não determinando os fins pelos quais esses vínculos seriam fixados" (Id.Ib., tradução nossa). A autora propõe um modelo alternativo no qual a cultura contém símbolos, rituais, histórias e guias de ação 
diversos e conflitantes. Ou seja, a cultura não é um sistema unificado que empurra a ação para uma direção consistente - como percebemos em Weber - , mas uma 'caixa de ferramentas' da qual os atores sociais se apropriam para selecionar os instrumentos mais adequados.

Partindo da própria teoria weberiana, Geertz e Swindler oferecem novos modelos teóricos em que os val ores são importantes na orientação da ação, mas não definindo os fins que a motivam. Os valores são importantes na medida em que são peças imprescindíveis na elaboração de estratégias de ação. A releitura de Max W eber realizada por eles é capaz de mostrar, concomitantemente, as possibilidades e os limites da teoria weberiana em relação à análise da cultura. E, de maneira muito sagaz, ambos também demonstram como as possibilidades da própria teoria, se bem exploradas, ajudam a suplantar tais limites.

\section{Referências bibliográficas}

COH N , Gabriel. Crítica eresignação. F undamentos da sociol ogia de M ax W eber. SP, T.A . Queiroz, 1979.

CUCHE, Denys. A noção de cultura nas ciências sociais. Bauru, Edusc, 1999. GEERTZ, Clifford. A interpretação das culturas. RJ, Zahar, 1978.

GOLDMAN, Harvey. Contemporary sociology and the interpretation of W eber. In: Theory and Sociedy, vol. 22 : (6), December 1993.

KALBERG, Stephen. On the neglect of Weber's Protestant Ethic as a theorical treatise: demarcating the parameters of postwar A merican sociological theory. In: Sociological Theory, vol. 14 : (1), March 1996.

M cINTOSH, Donald. Max Weber as a critical theorist. In: Theory and Society, vol. 12, 1983.

SCH LUCHTER, Wolfgang. The rise of western rationalism. M ax Weber's developmental history. Berkeley, U niversity of California Press, 1981, caps. II e III.

SW IN DLER, Ann. Culture in action: symbols and strategies. In: A merican Sociological R eview, Vol. 51 : (2), A pril 1986.

TUR N ER, Bryan. M ax W eber: from history to modernity. Londres, Routledge, 1993.

W EBER, Max. Rejeições religiosas do mundo e suas direções. $1^{\text {a }}$ edição 1915 In: GERTH, H ans H.\& MILLS, Charles Wright (org.). Ensai os de soci ol ogia. RJ, Guanabara-K oogan, 1982.

1992, pp. 118-154. . M etodologia das Ciências Sociais. Campinas, UN ICAM P, . A ética protestante e o espírito do capitalismo. 1ª edição 1905.

SP, Pioneira, 1996. 